\title{
Insecticidal activity of venomous saliva from Rhynocoris fuscipes (Reduviidae) against Spodoptera litura and Helicoverpa armigera by microinjection and oral administration
}

Sahayaraj K (1), Vinothkanna A (1)

(1) Crop Protection Research Centre, Department of Advanced Zoology and Biotechnology, St. Xavier's College, Palayamkottai, Tamil Nadu, India.

\begin{abstract}
Rhynocoris fuscipes is a potential predator of many economically important pests in India. In the present study, its venomous saliva (VS) was collected by milking and diluted with HPLC grade water to different concentrations (200, 400,600, 800 and 1000 ppm). Microinjection of Rhynocoris fuscipes VS was more toxic than its oral administration in Helicoverpa armigera (cotton bollworm) and Spodoptera litura (tobacco cutworm). Thus, R. fuscipes VS was found to be toxic to third instar S. litura and $H$. armigera with respective $L_{50} \mathrm{~s}$ of 846.35 and $861.60 \mathrm{ppm} /$ larva at 96 hours after microinjection. The current results showed that VS of Rhynocoris fuscipes caused mortality of $\mathrm{H}$. armigera and S. litura. Active peptides from VS may be isolated, identified and assessed for their impact in order to ascertain how they alter the physiology of these pests, information that could be applicable in pest management programs.
\end{abstract}

Key words: salivary venom, microinjection, oral administration, mortality, Rhynocoris fuscipes, biological control.

\section{INTRODUCTION}

Arthropod venom has attracted considerable interestasapotentialsourceofbioactivesubstances. Their biological properties and proteinaceous nature render them useful in biological pest management as previously suggested (1-5). The venom of poisonous predators has novel peptides that have been isolated from snakes, scorpions, marine cone snails, spider and other animals including predatory insects. In arthropods, copious information is available on spiders and parasitoids. Among the predatory hemipterans, reduviids constitute an important predator on account of presenting worldwide distribution and having been utilized in the biological control of cotton, soybean, groundnut and coconut pests. Venoms of reduviid predators are known to possess long-term, non-lethal paralytic effects on their prey. The immobilized or partially digested prey is then used as food by the reduviid predator (6-8). Such unique paralytic activity was due to the presence, in the venom of reduviid predators, of novel neurotoxic compounds, only a few of which have been isolated and characterized to date $(2,9-12)$.

The tobacco caterpillar, Spodoptera litura (Fabricius) is one of the most destructive pests and consists of about 120 species of plants belonging to 44 families $(13,14)$. The chemical control of $S$. litura presents limitations due to its resistance against many insecticides including pyrethroids $(15,16)$. The cotton bollworm, Helicoverpa armigera (Hübner), one of the most important pests, affects crop production globally (17). Insecticidal resistance of this pest has also been reported in the literature $(18,19)$.

The reduviid predator, Rhynocoris fuscipes Fab. (Hemiptera: Reduviidae) is an entomophagous insect distributed in many agroecosystems and 
feeds on more than 40 economically important insect pests in India (8). The potential of $R$. fuscipes as a biological control agent under laboratory and field conditions has been described previously (20-24). Maran (23) studied the paralytic potential of $R$. fuscipes salivary gland extract against selected pests. However, no one has studied the toxicological, physiological and immunological activities of this reduviid salivary venom on any pests. In the present work, we evaluated for the first time the biological activities of adult $R$. fuscipes salivary venom against $H$. armigera and S. litura third instar larvae.

\section{MATERIALS AND METHODS}

\section{Insect Collection and Rearing}

Laboratory colonies of the host species, $H$. armigera and S. litura, and the reduviid predator were established from individuals that were collected from cotton fields in Tamil Nadu, India. $R$. fuscipes were reared on the larvae of the host, $S$. litura at $30.0 \pm 1{ }^{\circ} \mathrm{C}$ and $70-80 \%$ relative humidity with a photoperiod of $11 / 13$ hours darkness/ light. The host colonies were maintained on fresh cotton leaves up to second instars, and then transferred to the freshly prepared artificial diet for further rearing.

\section{Venom Collection and Preparation}

The venomous saliva (VS) was collected from the ten-day-old freshly emerged adult reduviid as described previously $(25,26)$. The salivary venom collected from more than 50 reduviid predators was pooled and then stored on ice until used in our toxicity experiments within 12 hours. VS was collected from each predator only once. Concentrations of the VS $(200,400,600,800$ and $1000 \mathrm{ppm}$ ) were prepared by diluting with HPLCgrade water (Qualigens, India).

\section{Determination of Toxicity}

The toxicity of $R$. fuscipes VS was evaluated against third instar larvae of $H$. armigera and $S$. litura using microinjection and oral toxicity methods $(27,28)$. In the microinjection method, different VS concentrations were tested for toxicity by injecting $1.0 \mu \mathrm{L}$ of VS into each third stage S. litura larva of approximately $120 \mathrm{mg}$ in weight. Control category larvae were injected with HPLC-grade water. Salivary venom and water injected larvae were placed individually in a plastic container $(5.5 \mathrm{~cm}$ height $\mathrm{x} 3.8 \mathrm{~cm}$ diameter) and maintained in a BOD incubator on an artificial diet. Larval mortality was observed at 24 hours intervals up to 96 hours. Behavioral changes, if any, in the host insect were observed and recorded up to three hours post-injection. A soybean seed-based artificial diet was used to assay VS by oral delivery against newly hatched third stage S. litura larvae (starved for six hours prior to exposure to diet) (29).

For each treatment, six larvae were maintained in a sterilized plastic container containing moist filter paper to prevent diet desiccation. For the oral toxicity bioassay, $1 \mathrm{~mL}$ of VS of different concentrations $(200,400,600,800$ and 1000 ppm) was blended thoroughly with $100 \mathrm{mg}$ of artificial diet separately and provided to the larvae. Control diets contained an equal amount of HPLC-grade water. Survival was monitored daily up to 96 hours. A similar procedure was used for $H$. armigera third instar larvae.

\section{Statistical Analysis}

The $\mathrm{LD}_{50}$ value was calculated by the method of Finney (29). Control animal data were compared with different VS concentrations. All data were subjected to one-way ANOVA and post hoc Tukey's test using the statistical software SPSS (Version 11.5). The significance level was set at 5 or $1 \%$.

\section{RESULTS}

Individual $H$. armigera and S. litura injected with minimum concentrations (200 and 400 ppm) exhibited no initial response; but within 90 minutes the following sequence was observed: wriggling, restless movement, rapid mastication of the mandible, lateral fall and, finally, motionlessness. The onset of these symptoms seemed to occurring faster ( 30 to 40 minutes) with increasing concentrations. None of the control injections of $1.0 \mu \mathrm{L}$ HPLC-grade water resulted in fatality or symptoms of envenomation within 96 hours, the maximum period of observation.

\section{Microinjection Toxicity}

Spodoptera litura third instar larvae injected with VS, only $26.67 \%$ larvae died within 24 hours $(\mathrm{F}=9.42 ; \mathrm{df1}, 18 ; \mathrm{p}<0.01)$. However, at 96 hours, $64.29 \%$ of $S$. litura larvae had died $(\mathrm{F}=19.43$; df1,18; $\mathrm{P}<0.05)$ and showed an $\mathrm{LD}_{50}$ value of $861.60 \mathrm{ppm} /$ larva (Table 1). However, during the 
Table 1. Microinjection and oral administration of venomous saliva of $R$. fuscipes on the corrected mortality (\%) at different exposure moments (24, 48, 72 and 96 hours), $\mathrm{LC}_{30} \mathrm{LC}_{50}$ and LC (ppm) of Spodoptera litura and Helicoverpa armigera third instar larvae

\begin{tabular}{|c|c|c|c|c|c|c|c|c|}
\hline \multirow{3}{*}{$\begin{array}{l}\text { LD values } \\
\text { Concentration (ppm) }\end{array}$} & \multicolumn{4}{|c|}{ Microinjection } & \multicolumn{4}{|c|}{ Oral toxicity } \\
\hline & \multicolumn{4}{|c|}{ Hours after treatment } & \multicolumn{4}{|c|}{ Hours after treatment } \\
\hline & 24 & 48 & 72 & 96 & 24 & 48 & 72 & 96 \\
\hline \multicolumn{9}{|c|}{ Spodoptera litura third instar larvae } \\
\hline 200 & 13.33 & 33.33 & 42.86 & 42.86 & 0 & 0 & 13.33 & 21.43 \\
\hline 400 & 6.67 & 6.67 & 14.29 & 35.71 & 0 & 6.67 & 13.33 & 21.43 \\
\hline 600 & 13.33 & 40.00 & 35.71 & 50.00 & 6.67 & 20.00 & 26.67 & 35.71 \\
\hline 800 & 33.33 & 53.33 & 50.00 & 64.29 & 20.00 & 33.33 & 46.67 & 50.00 \\
\hline 1000 & 26.67 & 60.00 & 57.14 & 64.29 & 33.33 & 40.00 & 53.33 & 71.43 \\
\hline $\mathrm{LD}_{30}$ & - & 869.50 & 846.05 & 832.43 & - & - & 883.67 & 868.29 \\
\hline $\mathrm{LD}_{50}$ & - & 890.13 & 883.65 & 861.60 & - & - & 913.00 & 891.17 \\
\hline $\mathrm{LD}_{90}$ & - & 929.29 & 915.88 & 900.43 & - & - & 941.49 & 913.43 \\
\hline \multicolumn{9}{|c|}{ Helicoverpa armigera third instar larvae } \\
\hline 200 & 26.67 & 46.67 & 42.86 & 38.46 & 0.00 & 0.00 & 0.00 & 7.14 \\
\hline 400 & 33.33 & 40.00 & 35.71 & 38.46 & 6.67 & 7.14 & 7.69 & 14.29 \\
\hline 600 & 40.00 & 53.33 & 64.29 & 69.23 & 13.33 & 21.43 & 28.57 & 30.77 \\
\hline 800 & 46.67 & 73.33 & 78.57 & 76.92 & 20.00 & 21.43 & 28.57 & 46.15 \\
\hline 1000 & 53.33 & 80.00 & 78.57 & 84.62 & 20.00 & 42.86 & 50.00 & 69.23 \\
\hline $\mathrm{LC}_{30}$ & 863.19 & 816.56 & 820.14 & 822.31 & - & - & 891.22 & 881.63 \\
\hline $\mathrm{LD}_{50}$ & 906.24 & 847.29 & 847.13 & 846.35 & - & - & 928.12 & 899.91 \\
\hline $\mathrm{LC}_{90}$ & 947.51 & 877.11 & 873.41 & 869.83 & - & - & 960.82 & 917.48 \\
\hline
\end{tabular}

-: no results were found

same period, $84.62 \%$ of $H$. armigera larvae died with $\mathrm{LD}_{50}$ of $846.35 \mathrm{ppm} /$ larvae. VS of $R$. fuscipes caused dose-dependent mortality in both pests.

\section{Oral Toxicity}

At 24 and 48 hours of observation, VS caused less than $50 \%$ mortality in $H$. armigera and $S$. litura larvae. Oral administration of VS provoked respective mortalities of 71.43 and $69.23 \%$ in $S$. litura $(\mathrm{F}=19.42 ; \mathrm{df1}, 18 ; \mathrm{P}<0.05)$ and $H$. armigera $(\mathrm{F}=19.44 ; \mathrm{df1} 18 ; \mathrm{P}<0.05)$ larvae and $\mathrm{LD}_{50}$ values of 891.17 and $899.91 \mathrm{ppm} /$ larva (Table 1).

\section{DISCUSSION}

In the present study, the saliva from the reduviid predator was determined to be venomous 
to $H$. armigera and S. litura whether larvae received the treatment orally or by injection. The maximum corrected mortality of Spodoptera litura was observed at 96 hours with respective $\mathrm{LD}_{50} \mathrm{~s}$ of 861.60 and $891.17 \mathrm{ppm} / \mathrm{animal}$ for microinjection and oral administrations. For the same period and administration methods, $H$. armigera third instar larvae required more venom (Table 1), which indicates the pest is less susceptible than $S$. litura. The concentrations we administrated were biologically relevant. But it was reported previously that crude Paracoelotes luctuosus (Amaurobiidae) venom had an $\mathrm{LD}_{50}$ of 9-50 $\mu \mathrm{g} / \mathrm{g}$ against a prey species, $S$. litura showing that reduviid crude venom is more potent than spider toxin (2). Moreover, toxins isolated from spiders and scorpions also produced lower $\mathrm{LD}_{50}$ values against $S$. litura $(7.6,5.1$ and $14.4 \mu \mathrm{g} / \mathrm{g}$ for AalT, $\mathrm{LqhT}_{2}$ and $\mu$ AgalV, respectively).

Toxicity of three reduviids (Peirates turpi, Agriosphodrus dohrni and Isyndus obsurus) venoms were tested against $S$. litura larvae. The fact that they did not show any toxicity against the insects indicates that crude venom has more impact than such purified peptides as Ptul, Adl and Iobl (2). We concluded that the toxic nature of the VS is due to its protein content. However, isolation and identification VS peptides will be required in the near future. Previous reports of the toxic nature of Platymeris rhadamanthus, Peirates affinis and Haematorrhophus nigroviolaceous, Catamiarus brevipennis salivary venoms support our findings $(9,10,12,25)$. Injection of such venoms caused wriggling and restless movement, rapid mastication action of the mandible, a lateral fall and motionlessness for 30 to 40 minutes prior to resuming its routine activities. The paralysis was due to medium and low molecular weight neurotoxin (proteins). Edwards (9) reported that the salivary proteins of $P$. rhadamanthus provoke rapid loss of nervous conduction followed by loss of muscle contraction and relaxation. The study indicates that the venomous saliva is more toxic when injected directly into the insect haemocoel, completely bypassing the gut, which might be: consistent with the neuromuscular abnormalities we observed after injection of venom, or secondary consequences of a mixture of neurotoxic components in the venomous saliva of the reduviid. It is suggested to isolate, purify and identify the insecticidal compounds from reduviid VS.

\section{ACKNOWLEDGEMENTS}

K. Sahayaraj gratefully acknowledges the Department of Science and Technology (ref. n. SR/SO/AS - 33/2006), New Delhi, for the financial assistance. We thank the authorities of St. Xavier's College, Palayamkottai, for the laboratory facilities and encouragement.

\section{COPYRIGHT}

(C) CEVAP 2011

\section{SUBMISSION STATUS}

Received: May 19, 2011.

Accepted: September 2, 2011.

Abstract published online: September 9, 2011.

Full paper published online: November 30, 2011.

\section{CONFLICTS OF INTEREST}

There is no conflict.

\section{FINANCIAL SOURCE}

The Department of Science and Technology, Government of India, provided the financial grants (ref. n. SR/SO/AS - 33/2006).

\section{CORRESPONDENCE TO}

K. SAHAYARAJ, Crop Protection Research Centre, Department of Advanced Zoology and Biotechnology, St. Xavier's College, Palayamkottai, 627002, Tamil Nadu, India. Phone: +91 462 24264376. Fax: +91 4622561765. Email: ksraj42@gmail.com.

\section{REFERENCES}

1. Hammock BD, McCutchen BF, Beetham J, Choudary PV, Fowler E, Ichinose R, et al. Development of recombinant viral insecticides by expression of an insect-specific toxin and insect-specific enzyme in nuclear polyhedrosis viruses. Arch Insect Biochem Physiol. 1993;22(3-4):315-44.

2. Corzo G, Adachi-Akahane S, Nagao T, Kusui Y, NakajimaT. Novel peptides from assassin bugs (Hemiptra: Reduviidae): isolation, chemical and biological characterization. FEBS Lett. 2001;499(3):256-61.

3. de Castro CS, Silvestre FG, Araújo SC, Gabriel de MY, Mangili OC, Cruz I, et al. Identification and molecular cloning of insecticidal toxins from the venom of the brown spider Loxosceles intermedia. Toxicon. 2004;44(3):273-80.

4. Vassikeski AA, Kozlov SA, Samsonova SV, Egorova NS, Karpunin DV, Pluzhnikov KA, et al. Cyto-insectotoxins, a novel class of cytolytic and insecticidal peptides from spider venom. Biochem J. 2008;411(3):687-96. 
5. Chaim OM, Trevisan-Silva D, Chaves-Moreira D, Wille AC, Ferrer VP, Matsubara FH, et al. Brown spider (Loxosceles genus) venom toxins: tools for biological purposes. Toxins. 2011;3:309-44.

6. Blum SM. Biochemical defenses of insects. In: Rockstein M editor. Biochemistry of Insects. New York: Academic Press, 1978. p. 465-513.

7. Cohen AC. Feeding adaptations of some predaceous hemiptera. Ann Entomol Soc Am. 1990;83(6):121523.

8. Sahayaraj K. Trophic interactions. In: Pest control mechanism of reduviids. Jaipur: Oxford Book Company; 2007. p. 66-90.

9. Edwards JS. The action and composition of the saliva of an assassin bug Platymeris rhadamanthus Gaerst. (Hemiptera: Reduviidae). J Exp Biol. 1961;38:61-77.

10. Haridass ET, Ananthakrishnan TN. Functional morphology of salivary system in some Reduviidae (Insecta: Heteroptera). Proc Indian Acad Sci. 1981;90:145-60.

11. McMahan EA. Adaptations, feeding preferences and biometrics of a termite - baiting assassin bug. (Hemiptera: Reduviidae). Ann Entomol Soc Am. 1983;76(3):483-6.

12. Maran SPM, Ambrose DP. Paralytic potential of Catamiarus brevipennis (Serville), a potential biological control agent (Insecta: Heteroptera: Reduviidae). In: Ignacimuth A, Sen A, Janarthanan S (editors). Biotechnological applications for Integrated Pest Management. Oxford Publishing Co. Pvt. Ltd.: New Delhi, 2000. p. 125-31.

13. Hou-Guo Q, Zheng-Xiang Y, Shui-Jin H, Jian D, RenHua L. The correlations of the different host plants with preference level, life duration and survival rate of Spodoptera litura Fab. Chi J Eco-Agri. 2004;12:40- 42.

14. Kodandaram MH, Dhingra S. Variation in the toxicity of organophosphate insecticides to field populations of Spodoptera litura. Ind J Plant Prot. 2007;35(1):53-6.

15. Ahmad M, Saleem MA, Sayyed AH. Efficacy of insecticide mixtures against pyrethroid- and organophosphate-resistant populations of Spodoptera litura (Lepidoptera: Noctuidae). Pest Manag Sci. 2009;65(3):266-74.

16. Pratheepa MK, Meena K, Subramaniam KR, Venugopalan R, Bheemanna H. A decision tree analysis for predicting the occurrence of the pest, Helicoverpa armigera and its natural enemies on cotton based on economic threshold level. Current Sci. 2011;100(2):238-46.

17. Ramasubramanian T, Regupathy A. Laboratory measured resistance and field control of Helicoverpa armigera Hub. by thiodicarb. Asian J Plant Sci. 2003;2(17-24):1175-8.
18. Ramasubramanian $\mathrm{T}$, Regupathy A. Laboratory and field evaluation of spinosad against pyrethroid resistant population of Helicoverpa armigera Hub. J Biol Sci. 2004;4(2):142-5.

19. Ambrose DP, Claver MA. Functional response of Rhynocoris fuscipes Fabricius (Heteroptera: Reduviidae) Riptortus clavatus Thunberg (Heteroptera: Alydidae). J Biol Control. 1995;9(2):74-7.

20. Ambrose DP, Claver MA. Functional and numerical responses of the reduviid predator, Rhynocoris fuscipes F. (Heteroptera: Reduviidae) to cotton leafworm Spodoptera litura F. (Lepidoptera: Noctuidae). J Appl Entomol. 1997;121(6):331-6.

21. Claver MA, Ambrose DP. Functional response of the predator, Rhynocoris fuscipes (Heteroptera: Reduviidae) to three pests of pigeonpea (Cajanus cajan). Shashpa. 2002;9(1):47-51.

22. Claver MA, Ambrose DP. Suppression of Helicoverpa armigera (Hubner), Nezara viridula (L.) and Riptortus clavatus Thunberg infesting pigeonpea by the reduviid predator Rhynocoris fuscipes (Fabricius) in field cages. Entomol Croat. 2003;7(1-2):85-8.

23. Maran SP, Chosen reduviid predators prey interaction: Nutritional and kairomonal chemical ecology (Insecta: Heteroptera: Reduviidae). [Ph.D. thesis]. Tirunelveli, India: Manonmaniam Sundaranar University;(2000).

24. Sahayaraj K, Kumar SM, Anandh GP. Evaluation of milking and electrict shock methods for venom collection from hunter reduviids. Entomon. 2006;31(1):65-8.

25. Sahayaraj K, Kanna AV. Starvation impact on venom quantity of reduviid predator, Catamiarus brevipennis Servile. Entomon. 2009;34(2):119-21.

26. Escoubas P, Palma MF, Nakajima T. A microinjection technique using Drosophila melanogaster for bioassayguided isolation of neurotoxins in arthropod venoms. Toxicon. 1995;33(12):1549-55.

27. Gatehouse JA, M R Gatehouse A, Fitches E . Effects of snowdrop lectin (GNA) delivered via artificial diet and transgenic plants on the development of tomato moth (Lacanobia oleracea) larvae in laboratory and glasshouse trials. J Insect Physiol. 1997;43(8):727-39.

28. Mani C, Rao PJ. Comparative biology of Spodoptera litura (Fab.) on semisynthetic diet and natural food. Shaspha. 1998;5(2):141-4.

29. Finney DJ. Probit analysis. 4rd ed. London: Cambridge University;1971. 333p. 